\title{
Renal dysfunction reduces the diagnostic and prognostic value of serum CC16 for acute respiratory distress syndrome in intensive care patients
}

Jinle Lin ${ }^{1,2}$, Wuyuan Tao ${ }^{1,2}$, Jian Wei ${ }^{1}$, Jian $\mathrm{Wu}^{2^{*}}$, Wenwu Zhang ${ }^{1 *} \mathbb{D}$, Jianbing $\mathrm{Ye}^{1}, \mathrm{Xuan}_{\mathrm{Fu}}{ }^{1}$, Shiyong Zeng ${ }^{1}$, Qingli Dou', Lijun Wang ${ }^{3}$ and Fang Tian ${ }^{3}$

\begin{abstract}
Background: Contradictory results regarding changes in serum club cell protein 16 (CC16) levels in patients with acute respiratory distress syndrome (ARDS) have been reported, challenging the value of CC16 as a diagnostic and prognostic marker for ARDS. We have also observed increased serum CC16 levels in patients with renal dysfunction (RD). Therefore, the present study aimed to determine whether RD affects the diagnostic performance of CC16 for ARDS in intensive care unit (ICU) patients.

Methods: We measured serum CC16 concentrations in 479 ICU patients, who were categorized into six groups according to their diagnoses: control, acute kidney injury (AKI), chronic kidney disease (CKD), ARDS, ARDS+AKI, and ARDS+CKD. The sensitivity, specificity, and cutoff values for serum CC16 were assessed by receiver operating characteristic curve analysis.

Results: Serum CC16 concentrations were higher in the ARDS group than in the control group, and in ARDS patients with normal renal function, serum CC16 could identify ARDS and predict survival outcomes at 7 and 28 days. However, serum CC16 levels were similar among the ARDS+AKI, ARDS+CKD, AIK, and CKD groups. Consequently, in patients with AKI and/or CKD, the specificity of CC16 for diagnosing ARDS or ARDS+RD decreased from 86.62 to $2.82 \%$ or 81.70 to $2.12 \%$, respectively. Consistently, the CC16 cutoff value of $11.57 \mathrm{ng} / \mathrm{ml}$ in patients with RD differed from the established values of $32.77-33.72 \mathrm{ng} / \mathrm{ml}$ with normal renal function. Moreover, the predictive value of CC16 for mortality in ARDS+RD patients was lost before 7 days but regained by 28 days.

\footnotetext{
* Correspondence: sywujian@scut.edu.cn; eccm_bah@foxmail.com

Department of Respiratory, East Zone Sixth Division, Guangdong Provincial, People's Hospital, Guangdong Academy of Medical Science, Guangdong Provincial Geriatrics Institute, The second School of Clinical Medicine, Southern Medical University, No. 106, Zhongshan Second Road, Guangzhou 510000, Guangdong, China 'Department of Emergency Medicine, Affiliated Baoan Hospital of Shenzhen, Southern Medical University, 118 LongjingEr Road, Baoan, Shenzhen 518101, Guangdong, China
}

Full list of author information is available at the end of the article

(C) The Author(s). 2020 Open Access This article is licensed under a Creative Commons Attribution 4.0 International License, which permits use, sharing, adaptation, distribution and reproduction in any medium or format, as long as you give appropriate credit to the original author(s) and the source, provide a link to the Creative Commons licence, and indicate if changes were made. The images or other third party material in this article are included in the article's Creative Commons licence, unless indicated otherwise in a credit line to the material. If material is not included in the article's Creative Commons licence and your intended use is not permitted by statutory regulation or exceeds the permitted use, you will need to obtain permission directly from the copyright holder. To view a copy of this licence, visit http://creativecommons.org/licenses/by/4.0/ The Creative Commons Public Domain Dedication waiver (http://creativecommons.org/publicdomain/zero/1.0/) applies to the data made available in this article, unless otherwise stated in a credit line to the data. 
(Continued from previous page)

Conclusion: $\mathrm{RD}$ reduces the diagnostic specificity, diagnostic cutoff value, and predictive value for 7-day mortality of serum CC16 for ARDS among ICU patients.

Keywords: Acute respiratory distress syndrome, Acute kidney injury, Chronic kidney injury, Biomarkers, Club cell protein 16

\section{Background}

Acute respiratory distress syndrome (ARDS) is an acute lung disease with high mortality and morbidity in intensive care units (ICUs). No effective interventions have been established for its treatment, largely because the underlying physiological processes remain unknown. Early correct diagnosis is crucial to determine effective management. However, traditional methods, including $\mathrm{PaO}_{2} / \mathrm{FiO}_{2}$ measurement and X-ray, as mentioned in the Berlin definition, reveal changes that lag behind the actual progression of ARDS. Consequently, more than 20 potential biomarkers have been explored for their potential value in the diagnosis and prediction of ARDS in current studies [1], including the club cell protein (CC16).

CC16 is produced by club cells and was first described by the German anatomist Max Clara in 1937 [2]. The bronchial epithelium consists of $80 \%$ club cells, such as basal or nonciliated secretory cells, particularly in the distal bronchia [3]. According to previous studies, CC16, as the most abundant secretory protein found in the surface fluids of the airways, plays an important role in the maintenance and repair of lung airways [4]. Additionally, CC16 was reported as a potential biomarker of pulmonary injury caused by inhaled ozone, chlorine, and lipopolysaccharide (LPS) [2].

Five previous studies have evaluated the dynamics of CC16 expression in ARDS patients, but the results remain controversial. First, in 2006, a prospective multicenter observational study of 78 critical care patients conducted by the Quebec Critical Care Network found that an increase in the serum CC16 level was linked to the onset of ARDS as well as negative outcomes in ARDS patients [5]. In addition, Determann et al. reported increased plasma levels of CC16 in 22 patients with ventilator-associated pneumonia who developed ARDS. They found a better diagnostic capacity of CC16 at the cutoff point of $30 \mathrm{ng} /$ $\mathrm{ml}$ compared to surfactant Protein D, Krebs von den Lungen, and soluble receptor for advanced glycation end products. Interestingly, an increase in CC16 was seen prior to a diagnosis of ARDS [6]. Wutzler et al. further observed that increases in serum CC16 levels accompanied secondary respiratory complications in patients with multiple injuries [7]. In contrast, Kropski et al. found lower median plasma CC16 levels in ARDS patients than in patients with cardiogenic pulmonary edema $(22 \mathrm{ng} / \mathrm{ml}$ vs.
$55 \mathrm{ng} / \mathrm{ml}$ ) [8]. Furthermore, Ware et al. indicated that lower levels of CC16 (cutoff value at $9.2 \mathrm{ng} / \mathrm{ml}$ ) might help clinicians distinguish ARDS patients from sepsis patients [9]. The contradictory findings of these studies suggest that not only ARDS but also other factors influence serum CC16 levels.

Previously, we found that an increased serum CC16 level (cutoff point at $\geq 33.3 \mathrm{ng} / \mathrm{ml}$ ) can predict the onset of ARDS and is negatively correlated with the $\mathrm{PaO}_{2} /$ $\mathrm{FiO}_{2}$ ratio among ARDS patients [10]. However, we later observed that renal dysfunction (RD) separately raises the serum CC16 level. In the present study, we retrospectively evaluated whether RD interferes with the diagnostic performance of serum CC16 for ARDS in ICU patients.

\section{Methods \\ Study population}

From March 2013 to March 2015, patients admitted into our ICU were enrolled in the present study if they met the following criteria for inclusion: 1) age $>18$ and $<75$ years; 2) ICU stay of $>12 \mathrm{~h}$; 3) blood samples collected $<6 \mathrm{~h}$ after admission; and 4) diagnosis was confirmed before discharge. The Institutional Human Ethics Committee of affiliated Baoan Hospital of Shenzhen, Southern Medical University approved the protocols employed in this observational study. Written informed consent was obtained from each patient or their legal guardian.

\section{Data collection and laboratory examination}

Baseline data, including age, gender, blood pressure, body temperature, respiratory rate, heart rate, shock index, and $\mathrm{PaO}_{2} / \mathrm{FiO}_{2}$ ratio, were collected within $3 \mathrm{~h}$ after admission to the ICU. Seven-day mortality was recorded for all enrolled patients.

The levels of $\mathrm{N}$-terminal of the prohormone brain natriuretic peptide (NT-proBNP), albumin, and serum creatinine were synchronously measured within $3 \mathrm{~h}$ after admission.

All of the above data were compiled in a Microsoft Office Excel 2003 spreadsheet (Microsoft Corp., Seattle, WA, USA) for subsequent analysis.

\section{Diagnosis criteria}

ARDS was diagnosed according to the Berlin definition [11]: 1) acute course, < 7 days; 2) bilateral opacities consistent 
with pulmonary edema, as detected by computed tomography or X-ray; and 3) a $\mathrm{PaO}_{2} / \mathrm{FiO}_{2}$ ratio $<300 \mathrm{mmHg}$, with ventilation support (positive end expiratory pressure or continuous positive airway pressure $\geq 5 \mathrm{mmH}_{2} \mathrm{O}$ ).

Acute kidney injury (AKI) or chronic kidney disease (CKD) were diagnosed according to the clinical practice guidelines of the 2012 Kidney Disease Improving Global Outcomes organization [12]. AKI was defined by an increase in creatinine of $\geq 0.3 \mathrm{mg} / \mathrm{dL}(26.4 \mu \mathrm{mol} / \mathrm{ml})$ within $48 \mathrm{~h}$ or $\geq 50 \%$ above baseline, known or presumed to have occurred within the previous 7 days. CKD was defined by an estimated glomerular filtration rate $<60 \mathrm{ml} / \mathrm{min} \cdot 1.73 \mathrm{~m}^{2}$ for $>3$ months.

\section{Subgroup division}

Two senior physicians divided the patients into six subgroups after retrospectively reviewing patients' diagnoses based on their clinical conditions within $3 \mathrm{~h}$ after admission: 1) control group: ICU patients without ARDS or RD; 2) AKI group: AKI patients without ARDS; 3) CKD group: CKD patients without ARDS; 4) ARDS group: ARDS patients without RD; 5) ARDS+AKI group: ARDS patients with AKI; and 6) ARDS+CKD group: ARDS patients with CKD.

\section{Measurement of serum CC16}

Blood samples were immediately centrifuged at $3000 \mathrm{rpm}$ for $10 \mathrm{~min}$, and the serum was stored at $-60^{\circ} \mathrm{C}$ prior to analysis. The CC16 concentration was determined using an enzyme-linked immunosorbent assay kit ( $R \& D$ Systems, Minneapolis, MN, USA) following the manufacturer's instructions. A laboratory staff member blinded to patients' clinical data performed each assay in duplicate.

\section{Statistical analysis}

The data are presented as the mean \pm standard deviation or median (interquartile range) as indicated. Student's $t$ test or Mann-Whitney U test was used for comparisons between the groups when appropriate based on the normality of the data. Categorical data were compared using the $x^{2}$ or Kruskal-Wallis test. Differences among more than three subgroups were assessed using one-way analysis of variance. Linear correlations among the $\mathrm{PaO}_{2} /$ $\mathrm{FiO}_{2}$ ratio and serum levels of CC16, albumin, creatinine, and NT-proBNP were calculated using the Pearson linear correlation model. Receiver operating characteristic (ROC) curves were generated to assess the optimal cutoff value, sensitivity, and specificity values. A $P$-value $<0.05$ was considered statistically significant. Statistical analyses were performed using the SPSS software package (version 20.0; SPSS Inc., Chicago, IL, USA). Statistical graphs were created using GraphPad Prism 3.0 software (GraphPad Software Inc., La Jolla, CA, USA).

\section{Results}

Patients' baseline characteristics

A total of 479 critical care patients were recruited into our study, including 230 cases in the control group, 45 cases in the AKI group, 47 cases in the CKD group, 83 cases in the ARDS groups, 61 cases in the ARDS+AKI group, and 13 cases in the ARDS+CKD group. Lower blood pressure and higher incidence rates of pneumonia and sepsis were found in the ARDS and ARDS+AKI groups compared with the control group. However, higher blood pressure and a higher proportion of cardiogenic pulmonary edema were observed in the CKD and ARDS+CKD groups compared with the control group (Table 1). The reasons for ICU admission and outcomes of patients are described in Supplementary Tables 1 and 2. Relationship between serum CC16 levels with the severity of AKI or CKD was described in Supplementary Tables 3 and 4.

\section{Serum CC16 levels in six subgroups}

The serum CC16 concentration was higher in the ARDS group than in the control group $(47.78 \pm 19.92 \mathrm{ng} / \mathrm{ml}$ vs. $22.23 \pm 13.28 \mathrm{ng} / \mathrm{ml}, P=0.001)$. Even higher serum CC16 concentrations were observed in the following groups, with no significant differences among these groups: ARDS+AKI group $(64.89 \pm 20.47 \mathrm{ng} / \mathrm{ml})$, ARDS+CKD group $(72.21 \pm$ $18.63 \mathrm{ng} / \mathrm{ml})$, AKI group $(59.77 \pm 26.76 \mathrm{ng} / \mathrm{ml})$, and CKD group $(62.77 \pm 25.11 \mathrm{ng} / \mathrm{ml})$ (Fig. 1).

ROC curves for the diagnostic value of serum CC16 level in ARDS

We constructed ROC curves to evaluate the diagnostic performance of serum CC16 in the different groups of critical care patients (Table 2 and Fig. 2). Although the ROC curves for different groups showed a similar sensitivity, with RD as a baseline characteristic, the specificity for distinguishing ARDS from ARDS with a renal condition (AKI or CKD) decreased from 86.62 to $2.82 \%$ (ROC.1 vs. ROC.3) or 81.70 to $2.12 \%$ (ROC.2 vs. ROC.4). Consistently, a different cutoff value of 11.57 $\mathrm{ng} / \mathrm{ml}$ was found, which was lower than the previous values of $32.77 \mathrm{ng} / \mathrm{ml}$ and $33.72 \mathrm{ng} / \mathrm{ml}$.

\section{Correlation between serum CC16 levels and other clinical parameters}

Compared to the control group, the ARDS group had a higher concentration of serum $\mathrm{CC} 16$ and lower values for the $\mathrm{PaO}_{2} / \mathrm{FiO}_{2}$ ratio and albumin. However, decreased renal function in the AKI, CKD, ARDS+AKI, and ARDS+ CKD groups was consistently related to increased serum levels of CC16, NT-proBNP, and creatinine compared to those in the control and ARDS groups. Furthermore, Pearson correlation analysis showed that the serum $\mathrm{CC} 16$ level were positively correlated with the serum creatinine $(r=0.461$, Fig. 3a) and NT-proBNP $(r=0.400$, Fig. $3 \mathrm{~b})$ 
Table 1 Baseline characteristics of patients at admission

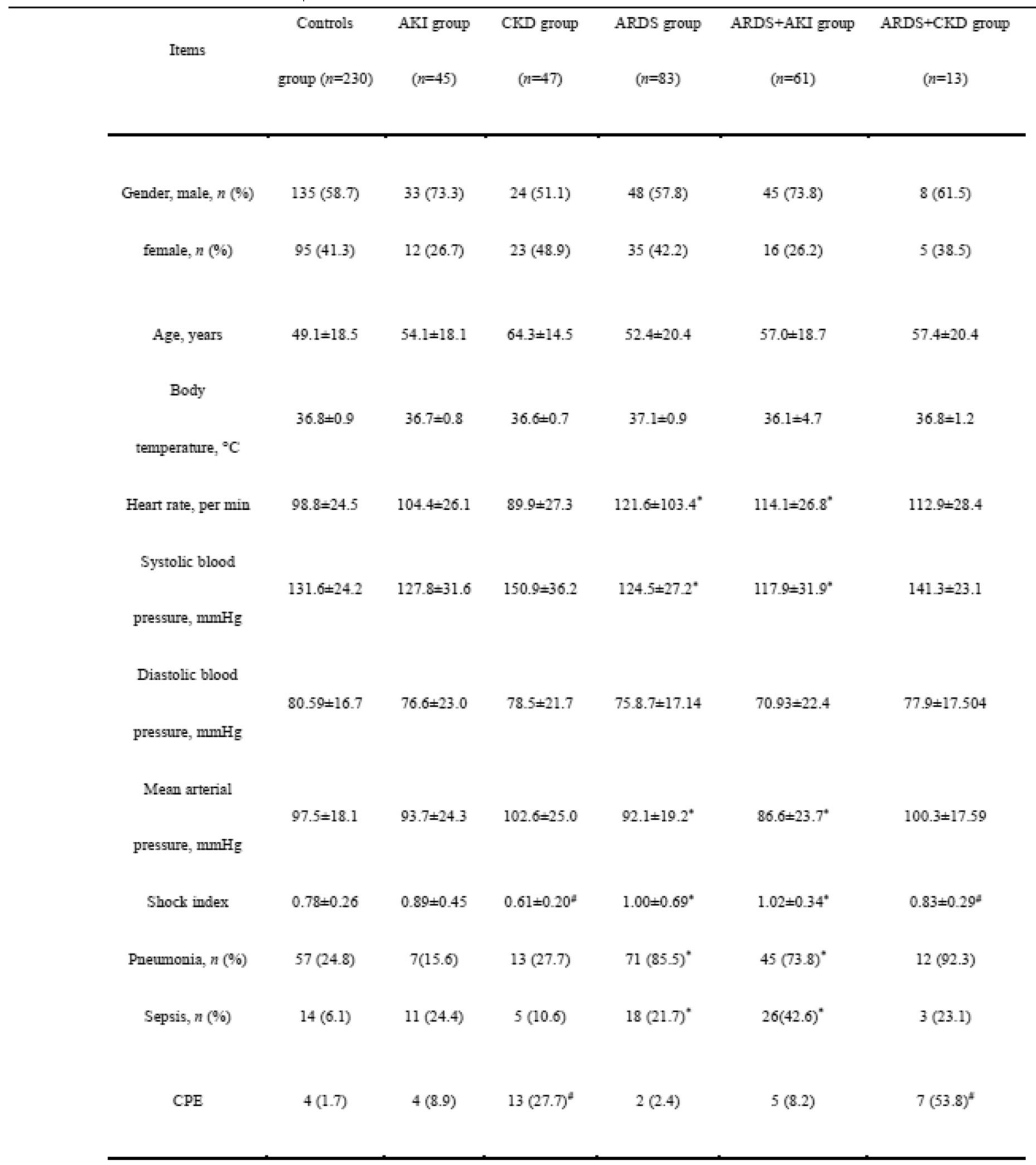

Note: Data were analyzed using Student's $t$ test or $x^{2}$ test. AKI, acute kidney injury; CKD Chronic kidney disease, ARDS Acute respiratory distress syndrome, CPE Cardiogenic pulmonary edema

${ }^{*} P<0.05$ between the ARDS group or ARDS+AKI group and the control group; $\# P<0.05$ between the CKD group or ARDS+CKD group and the control group

levels but negatively correlated with the $\mathrm{PaO}_{2} / \mathrm{FiO}_{2}$ ratio $(r=0 .-277$, Fig. 3c) and albumin level ( $r=-0.193$, Fig. 3d).

\section{Relationship between serum CC16 level and outcomes in ICU patients}

Increased serum CC16 levels were observed among nonsurviving patients in all groups, in relation to 7-day mortality (68 cases, $14.19 \%$ ) and 28 -day mortality (121 cases,
25.26\%) compared with the serum CC16 levels in the surviving patients of each group $(54.99 \pm 25.74 \mathrm{ng} / \mathrm{ml} \mathrm{vs}$. $38.57 \pm 25.76 \mathrm{ng} / \mathrm{ml}$ for 7 -day mortality; $51.01 \pm 25.89 *$ $\mathrm{ng} / \mathrm{ml}$ vs. $37.49 \pm 25.67 \mathrm{ng} / \mathrm{ml}$ for 28-day mortality). However, in the subgroup analysis, RD affected the predictive value of serum CC16 for 7-day mortality among the AKI group, CKD group, ARDS+AKI group, and ARDS+CKD group (Table 3). 


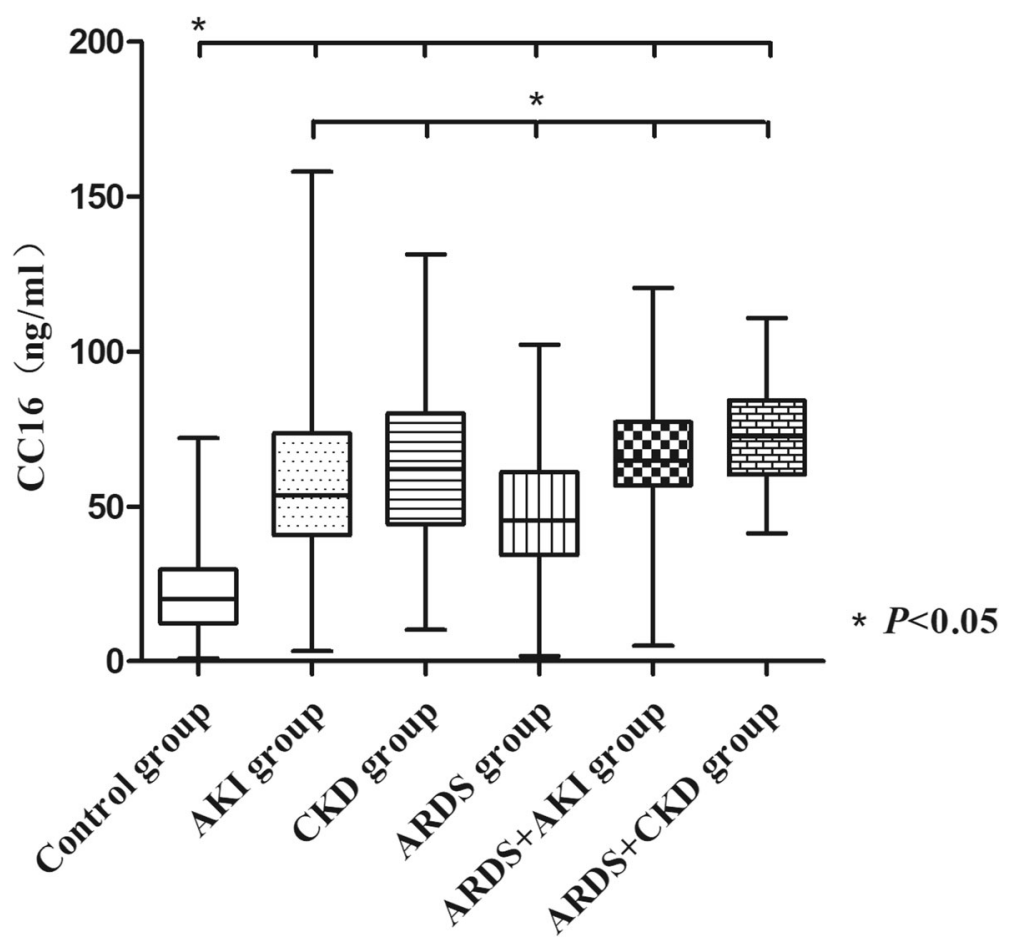

Fig. 1 Comparison of serum CC16 levels in the control group, AKI group, CKD group, ARDS group, ARDS+AKI group, and ARDS+CKD group. ${ }^{*} P<0.05$

\section{Discussion}

According to previous research by our group, increased serum CC16 levels can help clinicians identify ARDS in critical care patients with normal renal function [10], and this finding was confirmed in the present study. However, RD, whether in the form of AKI or CKD, also was found to raise the serum $\mathrm{CC} 16$ level, reducing the specificity of serum CC16 for ARDS and altering the diagnostic cutoff points for ARDS. Additionally, serum CC16 no longer offered predictive value for survival outcome at 7 days in patients who had RD.

An increase in the serum CC16 concentration depends not only on increased transportation of the protein from the bronchoalveolar lavage fluid but also on decrease

Table 2 Receiver operating characteristic (ROC) curves for the diagnostic value of serum club cell protein 16 (CC16) level for acute respiratory distress syndrome (ARDS) in different schemes

\begin{tabular}{cccccc}
\hline Scheme & AUC & SD & Sensibility & Specificity & Cutoff \\
\hline ROC.1 & 0.868 & 0.023 & $81.70 \%$ & $81.74 \%$ & 32.77 \\
ROC. 2 & 0.909 & 0.016 & $86.62 \%$ & $83.48 \%$ & 33.72 \\
ROC.3 & 0.341 & 0.041 & $98.78 \%$ & $2.82 \%$ & 11.57 \\
ROC. 4 & 0.456 & 0.038 & $98.72 \%$ & $2.12 \%$ & 11.57 \\
ROC.5 & 0.780 & 0.021 & $87.89 \%$ & $61.81 \%$ & 32.77
\end{tabular}

Notes: ROC Receiver operating characteristic, AUC Area under the curve, SD Standard deviation, AKI Acute kidney injury, CKD Chronic kidney disease, ARDS Acute respiratory distress syndrome. ${ }^{*} P<0.05$

ROC.1: ARDS group vs. control group:

ROC.2: ARDS group, ARDS+AKD group, and ARDS+CKD group vs. control group

ROC.3: ARDS group vs. AKI group and CKD group;

ROC.4: ARDS group, ARDS+AKD group, and ARDS+CKD group vs. AKI group and CKD group:

ROC.5: ARDS group, ARDS+AKD group and ARDS+CKD group vs. control group, AKI group and CKD group 


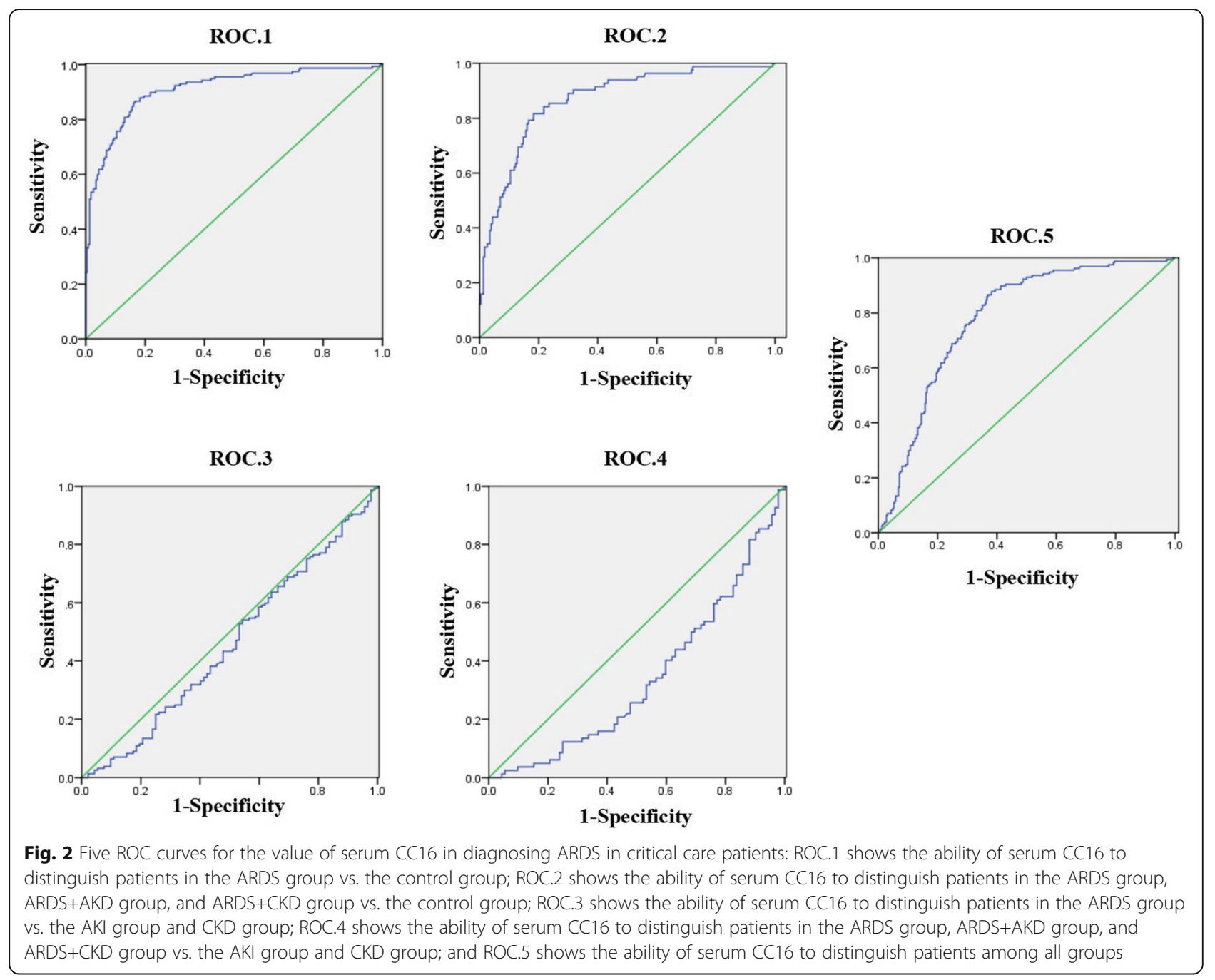

clearance of the protein in the kidney. Several previous studies have explored the value of the serum CC16 level for monitoring the permeability of the blood-air barrier, which shows a 1000-fold concentration gradient from bronchoalveolar lavage fluid $(0.5-1.5 \mathrm{mg} / \mathrm{L})$ to serum $(10-15 \mathrm{ng} / \mathrm{ml})$ in healthy nonsmokers. Therefore, increased CC16 levels have been reported in patents with multiple etiologies, such as chronic exposure to toxicants or severe air pollution [13-15]. However, CC16 has not been shown to be responsively synthesized, as evidenced by the negative correlation between serum CC16 and albumin levels in this study and previous research showing that the synthesis of albumin in response to ARDS can be rapidly reduced until the vascular compartment is repaired [16]. Furthermore, rapid renal clearance of serum CC16 with a half-life of approximately $2-3 \mathrm{~h}$ was previously found to occur via cubilin and/or megalin receptor-mediated endocytosis in the proximal tubule epithelial cells [17]. Andersson et al. showed that excretion of $\mathrm{CC} 16$ is related to the severity of renal damage, as measured by acute dimercaptosuccinic acid scintigraphy. Another clinical study indicated that the serum CC16 level may be able to predict creatinine clearance [18]. In addition, in vivo experiments have shown a significant increase in the serum CC16 level by 400 -fold over the basal value after paraquat-induced lung injury [19]; in that study, the increase in serum CC16 was mainly determined by the degree of renal impairment. Therefore, according to the literature, two conditions will increase the serum $\mathrm{CC} 16$ concentration in critical care patients: reduced permeability of the blood-air barrier and dysfunction of renal clearance [20].

Decreased renal function has been proven previously to be associated with an elevated NT-proBNP level [21]. In the present study, a worsening renal condition, whether AKI, CKD, ARDS+AKI, or ARDS+CKD, synchronously raised not only the serum $\mathrm{CC} 16$ concentration but also the NT-proBNP and creatinine concentrations. The positive relationship between these renal conditions and the CC16, creatinine, and NT-proBNP levels reflected a higher prevalence of cardiac pulmonary edema in the 


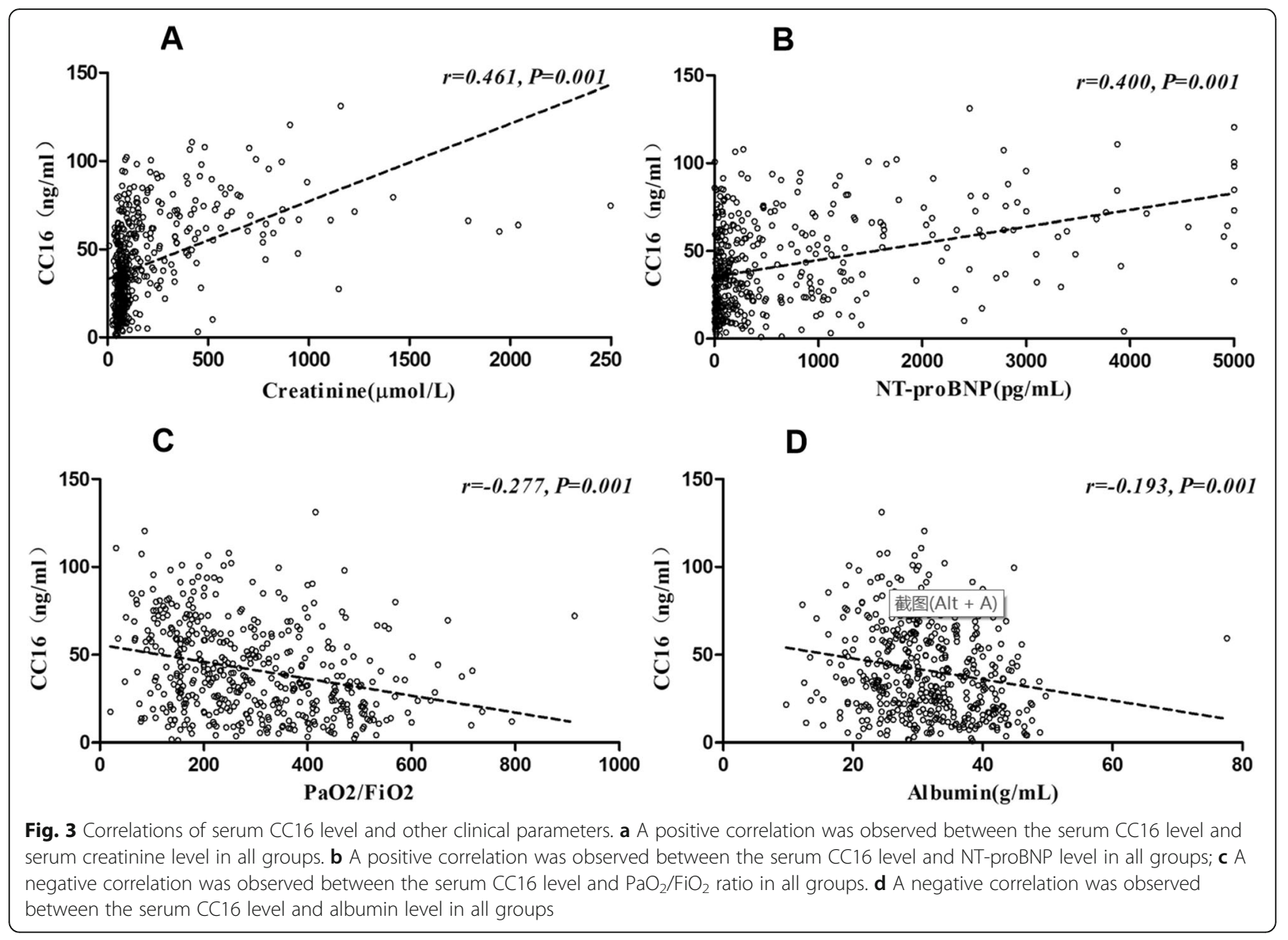

Table 3 Serum CC16 level and other clinical parameters in the six groups

\begin{tabular}{|c|c|c|c|c|c|c|}
\hline \multirow{3}{*}{ Items } & Control & AKI group & CKD group & ARDS group & ARDS+AKI group & ARDS+CKD group \\
\hline & & & & & & \\
\hline & group $(n=230)$ & $(n=45)$ & $(n=47)$ & $(n=83)$ & $(n=61)$ & $(n=13)$ \\
\hline $\mathrm{CCl} 16(\mathrm{ng} / \mathrm{mL})$ & $22.23 \pm 13.28$ & $59.77 \pm 26.76$ & $62.27 \pm 25.11$ & $47.78 \pm 19.92^{*}$ & $64.89 \pm 20.47$ & $72.21 \pm 18.63$ \\
\hline $\mathrm{PaO}_{2} / \mathrm{FiO}_{2}$ & $353.50=143.52$ & $345.09 \pm 147.46$ & $291.61=136.76$ & $204.19 \pm 84.71^{*}$ & $178.19 \pm 84.92$ & $205.77 \pm 137.15$ \\
\hline Creatinine $(\mathrm{mg} / \mathrm{mL})$ & $67.48 \pm 22.68$ & $358.23 \pm 335.55^{\#}$ & $583.15 \pm 438.233^{\#}$ & $72.03 \pm 24.19$ & $225.90 \pm 153.48$ & $633.05 \pm 630.61=$ \\
\hline
\end{tabular}

\section{NT-proBNP (pg/mL) $267.68 \pm 539.76983 .97 \pm 1020.23^{*} 1687.03 \pm 1389.56^{*} 421.74 \pm 756.901022 .99 \pm 1313.932402 .14 \pm 1662.05^{\sharp}$}

$$
\text { Albumin }(\mathrm{g} / \mathrm{mL}) \quad 33.48 \pm 8.10 \quad 29.83 \pm 7.23 \quad 31.92 \pm 6.17 \quad 28.21 \pm 6.44^{*} \quad 29.22 \pm 9.05 \quad 32.26 \pm 6.32
$$

Notes: CC16 Club cell protein 16, NT-proBNP N-terminal of the prohormone brain natriuretic peptide, AKI Acute kidney injury, CKD Chronic kidney disease, ARDS Acute respiratory distress syndrome

${ }^{*} P<0.05$ between the ARDS group and control group; ${ }^{*} P<0.05$ for the AKI group, CKD group, ARDS+AKI group, and ARDS+CKD group compared with the control group or ARDS group 
control group in a study by Kropski et al [8], which also observed baseline characteristics of cardiac pulmonary edema in their CKD and ARDS+CKD groups. Our analysis demonstrated that presentation of $\mathrm{RD}$ weakened the specificity and altered the cutoff value of serum CC16 for the diagnosis of ARDS, which may explain the conflicting results reported in the previous literature.

Although the serum CC16 level was not found to be associated with a 1-month clinical respiratory prognosis in a previous large, randomized trial investigation $(n=1200)$ [22], we found that an elevated serum CC16 level still predicted a poor outcome within 28 days in ICU patients with normal renal function. However, for patients with renal failure, this predictive value was lost within the first 7 days but regained by 28 days. Therefore, we propose that serum CC16 is still a useful biomarker for the diagnosis of and prognosis of ARDS in patients with normal renal function, especially given our previous finding that a reduced $\mathrm{CC} 16$ level can help clinicians predict the success of noninvasive ventilation among ICU patients [23]. Additionally, a decrease in the serum CC16 concentration might suggest a good prognosis, as this could be a sign of repair on the alveolar-capillary barrier in critical care patients. However, further studies are needed to prove this hypothesis.

Moreover, the biological role of an increased serum CC16 level in the ARDS process remains unclear. As an immunoregulatory protein, $\mathrm{CC} 16$ executes an antiinflammatory function by inhibiting phospholipase A2 activation and promoting the expression of inflammatory cascades (interleukin [IL]-1b, IL-8, etc.), TH2 cell differentiation, and the migration of neutrophils and monocytes $[24,25]$. Consistent with these findings, Pang et al. demonstrated that recombinant rat $\mathrm{CC} 16$ protein inhibits LPS-induced matrix metalloproteinase 9 expression and the production of pro-inflammatory cytokines via the nuclear factor- $\mathrm{kB}$ pathway in a model of tracheal epithelial cells and RAW264.7 macrophages [26, 27]. Those studies suggested that exogenous supplementation of recombinant CC16 could ameliorate cigarette smoke-induced lung inflammation in a murine disease model of chronic obstructive pulmonary disease [28]. Zhou et al. suggested that CC16 is an inhibitor of cell pyroptosis and inflammatory factors induced by LPS [29], demonstrating the potential value of $\mathrm{CC} 16$ in therapeutic efforts to repair acute lung injury induced by coronavirus disease 19 (COVID19). Further investigations of the function of $\mathrm{CC} 16$ in critical care patients are needed in the future.

A few limitations of the present study should be noted. First, as a comprehensive ICU, we enrolled only critical care patients and no healthy patients who may have received interventions potentially affecting the serum CC16 level. Although previous studies have revealed a relatively stable median $\mathrm{CC} 16$ level in normal controls $(5-7 \mathrm{ng} / \mathrm{ml})$, the median CC16 value in critical care patients in our control group appeared to be higher $(22.23 \pm 13.28 \mathrm{ng} / \mathrm{ml})$, likely because clinical conditions such as mechanical ventilation or primary graft dysfunction may promote the production of CC16 [30, 31]. This could have led to an unavoidable selection bias. However, the selection of ICU patients rather than healthy individuals as the control group for comparison is clinically meaningful for accurately diagnosing ARDS in the ICU. Second, we only monitored serum CC16 levels on admission, and the study lacked a parallel comparison with other promising biomarkers. Additional clinical research comparing the value of CC16 with that of other biomarkers for critical care patients is warranted with a broader range of patients. Thus, the exact diagnostic and prognostic roles of CC16 in ARDS require further investigation in a prospective study with a large sample size.

\section{Conclusion}

The present study confirmed that an increased serum CC16 level can help identify ARDS and predict the outcome in critical care patients with normal renal function. However, RD, in the form of either AKI or CKD, also raises the serum $\mathrm{CC} 16$ concentration, which reduces the specificity of CC16 for ARDS in these patients and alters the optimal cutoff points. Moreover, the predictive value of CC16 for the survival outcome in ARDS patients with $\mathrm{RD}$ is lost before 7 days but regained by 28 days.

\section{Supplementary information}

Supplementary information accompanies this paper at https://doi.org/10 1186/s12890-020-01245-0.

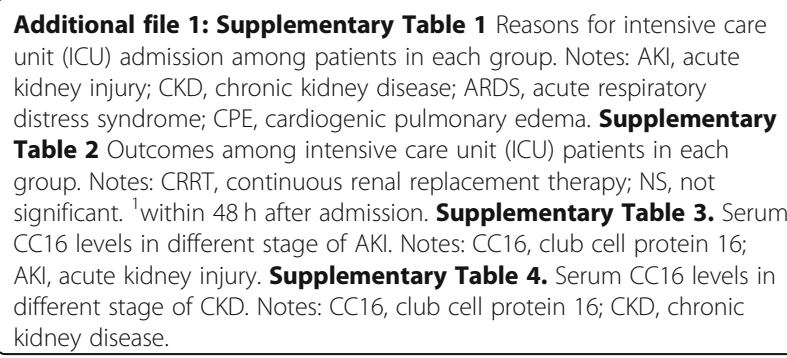

\section{Abbreviations}

AKI: Acute kidney injury; ARDS: Acute respiratory distress syndrome; CC16: Club cell protein 16; CKD: Chronic kidney disease; ICU: Intensive care unit; IL: Interleukin; LPS: Lipopolysaccharide; NT-proBNP: N-Terminal prohormone brain natriuretic peptide; RD: Renal dysfunction; ROC: Receiver operating characteristic curve; SBP: Systolic blood pressure

\section{Acknowledgments}

We thank all the investigators for their excellent assistance in this clinical research.

\section{Authors' contributions}

$J \mathrm{~L}, J W 2$ and WZ participated in the question conception, data analysis, and manuscript draft preparation. WT, JW1, JY, SZ and XF abstracted the data collection and Formal Analysis. QD, LW and FT provided critical appraisals of the study and helped with the development of the study question. The authors read and approved the final manuscript. 


\section{Funding}

The design of the study and collection was supported through funding from Jinle lin (The Science, Technology, \& Innovation Commission of Shenzhen Municipality, Grant Nos. JCYJ20180305123707368), the analysis and interpretation of data was supported through funding from Wunwu Zhang (The Science, Technology, \& Innovation Commission of Shenzhen Municipality, Grant Nos. JCYJ20170307094345589), the writing of manuscript was supported through funding from Jian Wu (National Natural Science Foundation of China, Grant Nos.81970012). All of funders equally contribute to this investigation.

\section{Availability of data and materials}

The data sets used and/or analyzed during the current study are available from the corresponding author on reasonable request.

\section{Ethics approval and consent to participate}

The Institutional Human Ethics Committee of affiliated Baoan Hospital of Shenzhen, Southern Medical University approved the study protocols employed in this observational study. Written informed consent was obtained from each subject or their legal guardians.

\section{Consent for publication}

Not Applicable.

\section{Competing interests}

The authors declare no conflict of interest.

\section{Author details}

'Department of Emergency Medicine, Affiliated Baoan Hospital of Shenzhen, Southern Medical University, 118 LongjingEr Road, Baoan, Shenzhen 518101, Guangdong, China. ${ }^{2}$ Department of Respiratory, Affiliated Baoan Hospital of Shenzhen, Southern Medical University, Shenzhen 518101, Guangdong, China. ${ }^{3}$ Department of Critical Care Medicine, East Zone Sixth Division, Guangdong Provincial People's Hospital, Guangdong Academy of Medical Science, Guangdong Provincial Geriatrics Institute, The second School of Clinical Medicine, Southern Medical University, No. 106, Zhongshan Second Road, Guangzhou 510000, Guangdong, China.

\section{Received: 7 April 2020 Accepted: 27 July 2020}

\section{Published online: 12 August 2020}

\section{References}

1. Garcia-Laorden MI, Lorente JA, Flores C, et al. Biomarkers for the acute respiratory distress syndrome: how to make the diagnosis more precise. Ann Transl Med. 2017;5(14):283

2. Wong AP, Keating A, Waddell TK. Airway regeneration: the role of the Clara cell secretory protein and the cells that express it. Cytotherapy. 2009;11(6): 676-87.

3. Boers JE, Ambergen AW, Thunnissen FB. Number and proliferation of basal and parabasal cells in normal human airway epithelium. Am J Respir Crit Care Med. 1998;157(6 Pt 1):2000-6.

4. Broeckaert F, Clippe A, Knoops B, et al. Clara cell secretory protein (CC16): features as a peripheral lung biomarker. Ann N Y Acad Sci. 2000;923:68-77.

5. Lesur $\mathrm{O}$, Langevin $\mathrm{S}$, Berthiaume $\mathrm{Y}$, et al. Outcome value of Clara cell protein in serum of patients with acute respiratory distress syndrome. Intensive Care Med. 2006;32(8):1167-74.

6. Determann RM, Millo JL, Waddy S, et al. Plasma CC16 levels are associated with development of ALL/ARDS in patients with ventilator-associated pneumonia: a retrospective observational study. BMC Pulm Med. 2009;9:49.

7. Wutzler S, Backhaus L, Henrich D, et al. Clara cell protein 16: a biomarker for detecting secondary respiratory complications in patients with multiple injuries. J Trauma Acute Care Surg. 2012;73(4):838-42.

8. Kropski JA, Fremont RD, Calfee CS, et al. Clara cell protein (CC16), a marker of lung epithelial injury, is decreased in plasma and pulmonary edema fluid from patients with acute lung injury. Chest. 2009;135(6):1440-7.

9. Ware $L B$, Koyama $T$, Zhao Z, et al. Biomarkers of lung epithelial injury and inflammation distinguish severe sepsis patients with acute respiratory distress syndrome. Crit Care. 2013;17(5):R253.

10. Lin J, Zhang W. Diagnostic and prognostic values of Club cell protein 16 (CC16) in critical care patients with acute respiratory distress syndrome. J Clin Lab Anal. 2018;32(2):e22262.
11. Force ADT, Ranieri VM, Rubenfeld GD, et al. Acute respiratory distress syndrome: the Berlin definition. JAMA. 2012;307(23):2526-33.

12. Levin A, Stevens PE, Bilous RW, et al. Kidney disease: improving global outcomes (KDIGO) CKD work group. KDIGO 2012 clinical practice guideline for the evaluation and management of chronic kidney disease. Kidney Int Suppl. 2013;3(1):1-150.

13. Hantson P, Bernard A, Hermans C. Kinetics and determinants of the changes of CC16, a lung secretory protein in a rat model of toxic lung injury. Clin Toxicol (Phila). 2008;46(3):230-8.

14. Provost EB, Chaumont $A$, Kicinski $M$, et al. Serum levels of club cell secretory protein (Clara) and short- and long-term exposure to particulate air pollution in adolescents. Environ Int. 2014;68:66-70.

15. St Helen GHN, Balmes JR, Hall DB, et al. Utility of urinary Clara cell protein (CC16) to demonstrate increased lung epithelial permeability in nonsmokers exposed to outdoor secondhand smoke. J Expo Sci Environ Epidemiol. 2013;23(2).

16. Ishida S, Hashimoto I, Seike T, et al. Serum albumin levels correlate with inflammation rather than nutrition supply in burns patients: a retrospective study. J Med Invest. 2014;61(3-4):361-8.

17. Amsellem S, Gburek J, Hamard G, et al. Cubilin is essential for albumin reabsorption in the renal proximal tubule. J Am Soc Nephrol. 2010;21(11):1859-67.

18. Andersson L, Preda I, Hahn-Zoric M, et al. Urinary proteins in children with urinary tract infection. Pediatr Nephrol. 2009;24(8):1533-8. http://www. pubmed.ncbi.nlm.nih.gov/19352723/.

19. Hantson P, Weynand B, Doyle I, et al. Pneumoproteins as markers of paraquat lung injury: a clinical case. J Forensic Leg Med. 2008;15(1):48-52.

20. Mekontso Dessap A, Ware LB, Bagshaw SM. How could biomarkers of ARDS and AKI drive clinical strategies? Intensive Care Med. 2016;42(5):800-2.

21. Potter JM, Simpson AJ, Kerrigan J, et al. The relationship of plasma creatinine (as eGFR) and high-sensitivity cardiac troponin and NT-proBNP concentrations in a hospital and community outpatient population. Clin Biochem. 2017;50(15):813-5.

22. Jensen JS, Itenov TS, Thormar KM, et al. Prediction of non-recovery from ventilator-demanding acute respiratory failure, ARDS and death using lung damage biomarkers: data from a 1200-patient critical care randomized trial. Ann Intensive Care. 2016;6(1):114.

23. Jianbin Y, Lin J, Chao Z, et al. The clinical value of combined detection of serum angiopoietin 2 and Clara cell protein 16 in the early diagnosis of acute respiratory distress syndrome. Chin J Emergency Med. 2019;28(9):1112-7.

24. Yoshikawa S, Miyahara T, Reynolds SD, et al. Clara cell secretory protein and phospholipase A2 activity modulate acute ventilator-induced lung injury in mice. J Appl Physiol. 2005;98(4):1264-71.

25. Johansson $\mathrm{S}$, Wennergren $\mathrm{G}$, Aberg $\mathrm{N}$, et al. Clara cell 16-kd protein downregulates $\mathrm{T}(\mathrm{H}) 2$ differentiation of human naive neonatal $\mathrm{T}$ cells. J Allergy Clin Immunol. 2007;120(2):308-14.

26. Pang M, Wang H, Bai IZ, et al. Recombinant rat CC16 protein inhibits LPSinduced MMP-9 expression via NF-kappaB pathway in rat tracheal epithelial cells. Exp Biol Med (Maywood). 2015;240(10):1266-78.

27. Pang $M$, Yuan $Y$, Wang $D$, et al. Recombinant $C C 16$ protein inhibits the production of pro-inflammatory cytokines via NF-KB and p38 MAPK pathways in LPS-activated RAW264.7 macrophages. Acta Biochim Biophys Sin. 2017:49(5):435-43.

28. Pang M, Liu H-Y, Li T, et al. Recombinant club cell protein 16 (CC16) ameliorates cigarette smoke-induced lung inflammation in a murine disease model of COPD. Mol Med Rep. 2018;18(2):2198-206.

29. Zhou R, Yang X, Li X, et al. Recombinant CC16 inhibits NLRP3/caspase-1induced pyroptosis through p38 MAPK and ERK signaling pathways in the brain of a neonatal rat model with sepsis. J Neuroinflammation. 2019;16(1):239.

30. Lesur O, Hermans C, Chalifour JF, et al. Mechanical ventilation-induced pneumoprotein CC-16 vascular transfer in rats: effect of KGF pretreatment. Am J Physiol Lung Cell Mol Physiol. 2003;284(2):L410-9.

31. Sarafidis K, Stathopoulou T, Agakidou E, et al. Comparable effect of conventional ventilation versus early high-frequency oscillation on serum CC16 and IL-6 levels in preterm neonates. J Perinatol. 2011;31(2):104-11.

\section{Publisher's Note}

Springer Nature remains neutral with regard to jurisdictional claims in published maps and institutional affiliations. 